\title{
Photoluminescence, thermally stimulated luminescence and electron paramagnetic resonance of europium-ion doped strontium pyrophosphate
}

\author{
V. Natarajan ${ }^{\mathrm{a}}$, M.K. Bhide ${ }^{\mathrm{b}}$, A.R. Dhobale ${ }^{\mathrm{a}}$, S.V. Godbole ${ }^{\mathrm{b}}$, T.K. Seshagiri ${ }^{\mathrm{b}}$, \\ A.G. Page ${ }^{\mathrm{b}}$, Chung-Hsin $\mathrm{Lu}^{\mathrm{a}, *}$ \\ a Department of Chemical Engineering, No. 1, Sec. 4, Roosevelt Road, National Taiwan University, Taipei 106, Taiwan \\ ${ }^{\mathrm{b}}$ Radiochemistry Division, Bhabha Atomic Research Centre, Trombay, Mumbai
}

Received 19 March 2004; received in revised form 18 June 2004; accepted 13 July 2004

\begin{abstract}
Europium-ion doped strontium pyrophosphate was prepared via a chemical precipitation method to investigate the fluorescence of europium ions, the phosphate radical ions formed upon gamma-ray irradiation and their role in the thermally stimulated luminescence (TSL) of this compound. Fluorescence spectra revealed that europium ions were present in divalent as well as trivalent oxidation states. The measurements of fluorescence life time indicated that $\mathrm{Eu}^{3+}$ ions existed in two different types of environments in the lattice. Gamma irradiated europium-ion doped $\mathrm{Sr}_{2} \mathrm{P}_{2} \mathrm{O}_{7}$ showed the presence of two thermo-luminescence glow peaks at 465 and $565 \mathrm{~K}$; however, no glow was observed in the undoped sample. Electron paramagnetic resonance (EPR) studies of europium-ion doped samples showed signals from $\mathrm{Mn}^{2+}$ ions (present as impurity) prior to and after gamma irradiation. Upon gamma irradiation, signals originating from $\mathrm{PO}_{2}{ }^{2-}, \mathrm{PO}_{3}{ }^{2-}$ and $\mathrm{O}_{2}{ }^{-}$radical ions were observed in the undoped and doped samples. In the gamma irradiated europium-ion doped samples, additional low-field EPR signals, attributed to $\mathrm{Eu}^{2+}$ ions, were observed. By correlating the TSL and EPR results on europium-ion doped $\mathrm{Sr}_{2} \mathrm{P}_{2} \mathrm{O}_{7}$, the mechanism for the glow peak at $565 \mathrm{~K}$ was identified.
\end{abstract}

(C) 2004 Elsevier Ltd. All rights reserved.

Keywords: A. Amorphous materials; B. Chemical synthesis; D. Defects; D. Electron paramagnetic resonance; D. Luminescence

* Corresponding author. Tel.: + 88622365 1428; fax: +886 223623040.

E-mail address: chlu@ccms.ntu.edu.tw (C.-H. Lu). 


\section{Introduction}

Rare earth activated inorganic phosphors are widely used in a variety of applications, such as lamp industry, color display, radiation dosimetry and X-ray imaging. In particular, the luminescent properties of europium-ion activated phosphors have been studied extensively for their applications in these areas [1]. The emission of $\mathrm{Eu}^{2+}$ ions varies from blue to red depending on the host lattice due to crystal-field effects [2]. In view of the general interest in the green and yellow emitting $\mathrm{Eu}^{2+}$ activated compositions in recent years, calcium and strontium silicates and phosphates have been investigated in detail $[3,4]$. Further investigations on the luminescent characteristics of $\mathrm{Eu}^{2+}$ activated alkaline earth aluminates have been reported in view of their potential application in luminous paints [5]. Strontium halophosphate doped with $\mathrm{Eu}^{2+}$ ions has been reported to be useful for thermo-luminescence dosimetry [6], while $\mathrm{Eu}^{2+}$ activated strontium borate $\left(\mathrm{SrB}_{4} \mathrm{O}_{7}\right)$ and strontium pyrophosphate $\left(\mathrm{Sr}_{2} \mathrm{P}_{2} \mathrm{O}_{7}\right)$ phosphors have been reported to be applicable in photo-therapy [7].

$\mathrm{Eu}^{2+}$ activated strontium pyrophosphate is considered to be a potential candidate for use in lamps for photo-therapy of hyper bilirubinemia (infant jaundice), since its emission is at $420 \mathrm{~nm}$ with negligible contribution from ultra-violet radiation; and hence, will be safe for treating infants. In fact, $\mathrm{Eu}^{2+}$ and $\mathrm{Mn}^{2+}$ co-doped $\mathrm{Sr}_{2} \mathrm{P}_{2} \mathrm{O}_{7}$ has been suggested as one of the potential phosphors, to be used in the phosphor mixture for obtaining white light emission from UV LED devices [8]. Although, fluorescence studies on $\mathrm{Sr}_{2} \mathrm{P}_{2} \mathrm{O}_{7}: \mathrm{Eu}^{2+}$ has been reported long ago by Blasse et al. [9], there are no reported investigations on the thermally stimulated luminescence (TSL) and electron paramagnetic resonance (EPR) of this system, as far as we know. There is indeed one report on the TSL and EPR of $\mathrm{Tm}^{3+}$ activated $\mathrm{Ca}_{2} \mathrm{P}_{2} \mathrm{O}_{7}$ [10]. In view of these, $\mathrm{Sr}_{2} \mathrm{P}_{2} \mathrm{O}_{7}$ doped with Eu ions $(0.5$ at.\%) was prepared in our study via a chemical precipitation method, followed by heating the sample in nitrogen atmosphere and was investigated using fluorescence, TSL and EPR techniques in order to understand the role of europium ions in fluorescence and TSL properties. In this paper, the evidence for the co-existence of $\mathrm{Eu}^{2+} \mathrm{and}^{3+}$ in the samples is presented. In addition, the gamma radiation induced defect centers formed in this lattice were identified and their role in the TSL glow peaks was examined.

\section{Experimental}

Strontium hydrogen phosphate was precipitated from strontium nitrate solution containing $\mathrm{Eu}^{3+}$ $(0.5$ at. $\%)$ by adding diammonium hydrogen phosphate. The $\mathrm{pH}$ of the solution was adjusted to be around 7-8. Analytical grade strontium nitrate, diammonium hydrogen phosphate and very pure $\mathrm{Eu}_{2} \mathrm{O}_{3}$ $(99.999 \%)$ were used for the preparation. The precipitate was filtered and dried with alcohol. Later, it was ground thoroughly and heated at $1173 \mathrm{~K}$ for $3-4 \mathrm{~h}$ in nitrogen atmosphere. X-ray diffraction analysis of the sample confirmed that the compound formed was $\alpha-\mathrm{Sr}_{2} \mathrm{P}_{2} \mathrm{O}_{7}$ [11]. Undoped $\operatorname{Sr}_{2} \mathrm{P}_{2} \mathrm{O}_{7}$ sample was also prepared in a similar way. About $20 \mathrm{mg}$ of the samples was used for TSL measurements carried out on a home-built unit between 300 and $700 \mathrm{~K}$. The samples were irradiated with $\mathrm{Co}^{60}$ rays inside a gamma chamber. Photoluminescence spectra were recorded using a Hitachi 2000 fluorescence spectrometer equipped with a $150 \mathrm{~W}$ Xe arc lamp. Fluorescence lifetime measurements were carried out using an Edinburgh Fluorescence lifetime spectrometer equipped with a hydrogen flash lamp having a pulse width of 1-2 ns. EPR spectra were recorded using a Bruker ESP-300 spectrometer at x-band frequencies both at room temperature and $77 \mathrm{~K}$. Spectra were also recorded at different temperatures 
ranging from 100-400 K using a Bruker low temperature accessory. Further, spectra of the gamma irradiated samples were recorded after annealing in the temperature range of 450-575 K.

\section{Results and discussion}

\subsection{Luminescence of europium-ion doped $\mathrm{Sr}_{2} \mathrm{P}_{2} \mathrm{O}_{7}$}

Europium ions can be stabilized in $\mathrm{Sr}_{2} \mathrm{P}_{2} \mathrm{O}_{7}$ lattice in either divalent or trivalent oxidation state. The incorporation and stabilization of $\mathrm{Eu}$ ions in the sample were confirmed by the luminescence investigations. The fluorescence spectra of the samples are shown in Figs. 1 and 2. The emission spectra corresponding to excitation of $\mathrm{Eu}^{3+}$ at 256 and $270 \mathrm{~nm}$ are depicted in Fig. 1 with two peaks at 594 and $615 \mathrm{~nm}$. The excitation spectra corresponding to these peaks are also shown in the figure. The characteristic excitation and emission spectra of $\mathrm{Eu}^{2+}$ ions are illustrated in Fig. 2.

It is obvious from Fig. 1 that emission peaks characteristic of $\mathrm{Eu}^{3+}$ ions are present in the samples. The emission peaks at 594 and $615 \mathrm{~nm}$ corresponding to ${ }^{5} \mathrm{D}_{0} \rightarrow{ }^{7} \mathrm{~F}_{1}$ and ${ }^{5} \mathrm{D}_{0} \rightarrow{ }^{7} \mathrm{~F}_{2}$ transitions, respectively, are observed on excitation with both 256 and $270 \mathrm{~nm}$. The emission peak intensity ratio $(R)$ of ${ }^{5} \mathrm{D}_{0} \rightarrow{ }^{7} \mathrm{~F}_{2}$ to that of ${ }^{5} \mathrm{D}_{0} \rightarrow{ }^{7} \mathrm{~F}_{1}$ transition is known to provide structural information [12]. As seen from the data illustrated in Fig. 1, the intensity ratio $(R)$ of the sample varies with excitation wavelength $(256$ and $270 \mathrm{~nm})$. The changes in the intensity ratio suggest the existence of $\mathrm{Eu}^{3+}$ ions at two different sites in $\mathrm{Sr}_{2} \mathrm{P}_{2} \mathrm{O}_{7}$ lattice corresponding to two charge transfer excitation peaks. The crystallographic data of $\mathrm{Sr}_{2} \mathrm{P}_{2} \mathrm{O}_{7}$ are reported to contain two types of sites for $\mathrm{Sr}^{2+}$ ions in the unit cell [13]. The differences in the spectra thus reveal that $\mathrm{Eu}^{3+}$ ions are situated at the two types of sites corresponding to $\mathrm{Sr}^{2+}$ ions. On excitation with $256 \mathrm{~nm},{ }^{5} \mathrm{D}_{0} \rightarrow{ }^{7} \mathrm{~F}_{1}$ emission at $594 \mathrm{~nm}$ is the predominant one, while ${ }^{5} \mathrm{D}_{0} \rightarrow{ }^{7} \mathrm{~F}_{2}$ emission

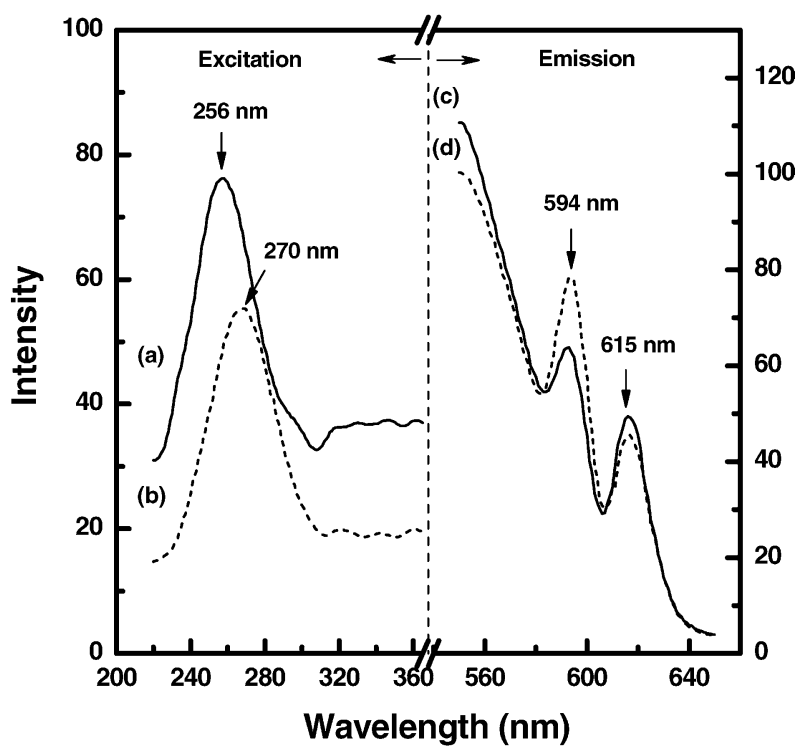

Fig. 1. Excitation spectra of $\mathrm{Eu}^{3+}$ in europium doped $\mathrm{Sr}_{2} \mathrm{P}_{2} \mathrm{O}_{7}$ corresponding to (a) emission peak at $594 \mathrm{~nm}$ and (b) emission peak at $615 \mathrm{~nm}$. Emission spectra of $\mathrm{Eu}^{3+}$ ion corresponding to (c) excitation spectra at $256 \mathrm{~nm}$ and (d) excitation at $272 \mathrm{~nm}$. 


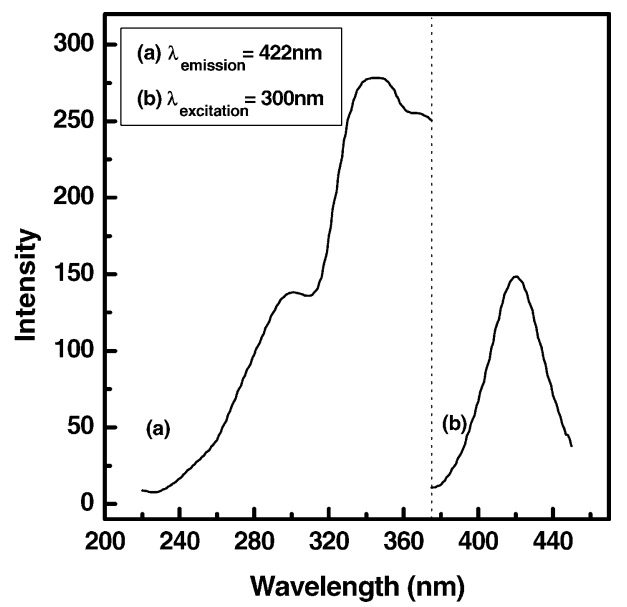

Fig. 2. (a) Excitation and (b) emission spectra of $\mathrm{Eu}^{2+}$ ion in europium doped $\mathrm{Sr}_{2} \mathrm{P}_{2} \mathrm{O}_{7}$.

at $615 \mathrm{~nm}$ is relatively weak. The peak at $615 \mathrm{~nm}$ is due to ${ }^{5} \mathrm{D}_{0} \rightarrow{ }^{7} \mathrm{~F}_{2}$ transition, which is parity forbidden and observed only when the lattice environment is distorted and contains non-inversion symmetry. Being a forced electric-dipole transition, this transition is hypersensitive to the environment. Therefore, it is inferred that the 256-nm excited emission peaks at 594 and $615 \mathrm{~nm}$ correspond to $\mathrm{Eu}^{3+}$ ions occupying a site with a smaller deviation from inversion symmetry. On the other hand, $270 \mathrm{~nm}$ excitation leads to the observation of 594 and $615 \mathrm{~nm}$ emission with nearly same intensity. This indicates that the emission originates from $\mathrm{Eu}^{3+}$ ions occupying sites lacking inversion symmetry.

The luminescence spectra illustrated in Fig. 2 reveal that $\mathrm{Eu}^{2+}$ ions with characteristic emission at $422 \mathrm{~nm}$, are also formed during synthesis. This observation suggests that synthesis conditions help in the partial reduction of $\mathrm{Eu}^{3+}$ ions to $\mathrm{Eu}^{2+}$ ions and inert atmosphere facilitates the partial reduction of $\mathrm{Eu}^{3+}$ to $\mathrm{Eu}^{2+}$. The excitation spectra monitored for $422 \mathrm{~nm}$ contain broad and strong peaks at 300 and $330 \mathrm{~nm}$. As compared to the emission from $\mathrm{Eu}^{3+}$ ions, the emission spectra of $\mathrm{Eu}^{2+}$ ions were recorded at lower PM tube voltage as the signals were very intense, if recorded at identical PM tube voltage. The strong emission due to $\mathrm{Eu}^{2+}$ ions is associated with the allowed transitions of $5 \mathrm{~d} \rightarrow 4 \mathrm{f}$. The fluorescence lifetime for emission from $\mathrm{Eu}^{3+}$ ions were determined to be 110 and $522 \mu \mathrm{s}$ by monitoring the $594 \mathrm{~nm}$ peak. For $\mathrm{Eu}^{2+}$ ions, the life time was determined to be $1.6 \mu$ s by monitoring at $422 \mathrm{~nm}$. These values are consistent with the forbidden and allowed nature of transition involving these ions.

\subsection{TSL of europium-ion doped $\mathrm{Sr}_{2} \mathrm{P}_{2} \mathrm{O}_{7}$}

TSL glow curves of the Eu-ion doped $\mathrm{Sr}_{2} \mathrm{P}_{2} \mathrm{O}_{7}$ samples exposed to 100 and $200 \mathrm{~Gy}$ doses of $\mathrm{Co}^{60}$ gamma-rays were recorded. Two glow peaks were observed around 465 and $565 \mathrm{~K}$ (heating rate $=5 \mathrm{~K} / \mathrm{s}$ ) and the latter one is more intense than the former one (Fig. 3). The glow is not strong enough for recording the emission spectra. However, a red glow could be seen visually on heating the irradiated samples at 465 and $565 \mathrm{~K}$, indicating that $\mathrm{Eu}^{3+}$ acts as the luminescent center for the glow peaks. On the other hand, the undoped $\mathrm{Sr}_{2} \mathrm{P}_{2} \mathrm{O}_{7}$ sample did not show any TSL peak. 


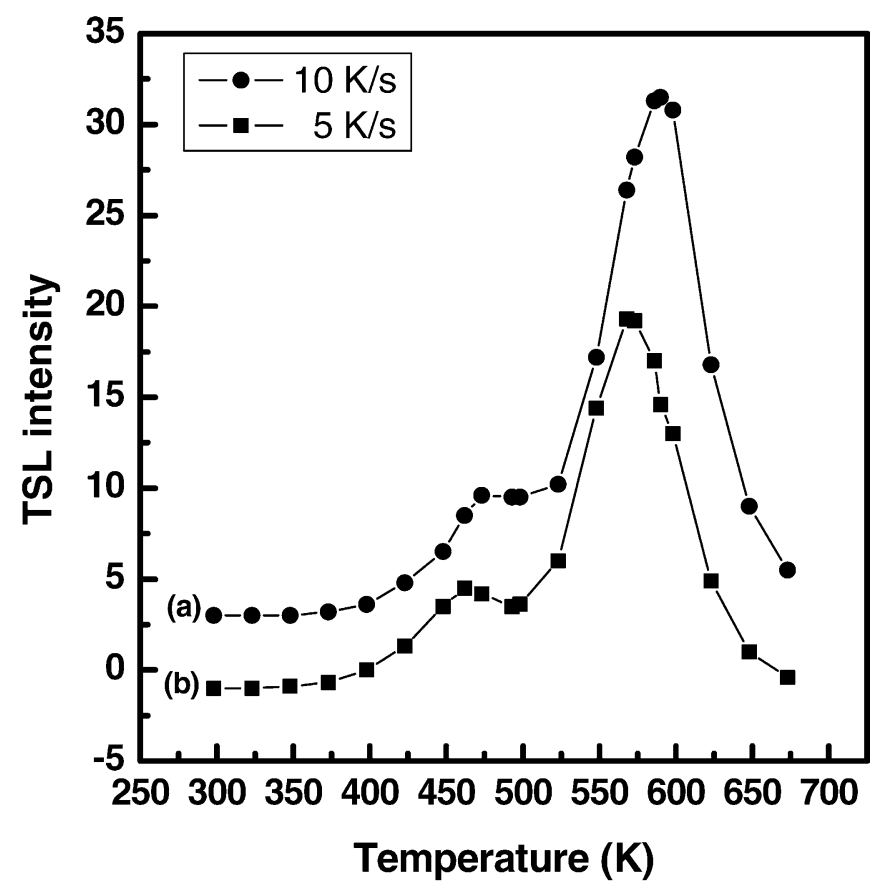

Fig. 3. TSL glow curves of 200 Gy gamma-ray irradiated europium-ion doped $\mathrm{Sr}_{2} \mathrm{P}_{2} \mathrm{O}_{7}$ sample recorded at the heating rates of $5 \mathrm{~K} / \mathrm{s}$ and $10 \mathrm{~K} / \mathrm{s}$.

\subsection{EPR of europium-ion doped and undoped $\mathrm{Sr}_{2} \mathrm{P}_{2} \mathrm{O}_{7}$}

To clearly distinguish the signals of $\mathrm{Sr}_{2} \mathrm{P}_{2} \mathrm{O}_{7}$ from those of Eu-ion doped $\mathrm{Sr}_{2} \mathrm{P}_{2} \mathrm{O}_{7}$ and also to identify the radical ions formed on gamma irradiation, EPR spectra of Eu-ion doped and undoped $\mathrm{Sr}_{2} \mathrm{P}_{2} \mathrm{O}_{7}$ samples were recorded before and after gamma irradiation with a dose of $2-4 \mathrm{kGy}$. It should be borne in mind that TSL is at least three to four orders more sensitive than EPR in the detection of small concentration of defects. Hence, for interpreting TSL mechanisms, EPR measurements were carried out on samples subjected to higher irradiation doses as compared to TSL experiments in order to produce significant quantities of the paramagnetic centers.

EPR spectra of the unirradiated and gamma irradiated $\mathrm{Sr}_{2} \mathrm{P}_{2} \mathrm{O}_{7}$ samples were recorded at room temperature and $77 \mathrm{~K}$. At room temperature, EPR spectrum of unirradiated $\mathrm{Sr}_{2} \mathrm{P}_{2} \mathrm{O}_{7}$ did not show any signal, while that of the gamma irradiated (dose $=4 \mathrm{kGy}$ ) sample consisted of a composite signal of eight lines centered around $3.4 \mathrm{kG}(g=2.0)$ along with a doublet signal with a large separation $(A=740 \mathrm{G})$ with $g=2.0303$. The composite signal has a set of five intense lines in addition to a triplet with moderate intensity (Fig. 4). The microwave power dependence of this signal in the range of $2-24 \mathrm{~mW}$ indicated different saturation behavior of the doublet $(A=740 \mathrm{G})$ signal centered at $g=2.0303$ ( $\mathrm{P}_{1}$ center) as compared to that of the composite signal at $g=2.0$. In order to identify the origins of radicals contributing to the composite signal, EPR spectrum of a sample irradiated with low gamma dose (1 kGy) was investigated. EPR spectrum of the low dose sample was recorded at room temperature, which showed dose dependent saturation of the most intense signal at $g=2.00472\left(\mathrm{P}_{2}\right.$ center $)$. Thus, a quartet of intense lines with $A_{\perp}=57.8 \mathrm{G}$ and $A_{\|}=121.84 \mathrm{G}, A_{\text {iso }}=79.1 \mathrm{G}$ and $g_{\perp}=2.0041$ and $g_{\|}=2.0042$ have different 


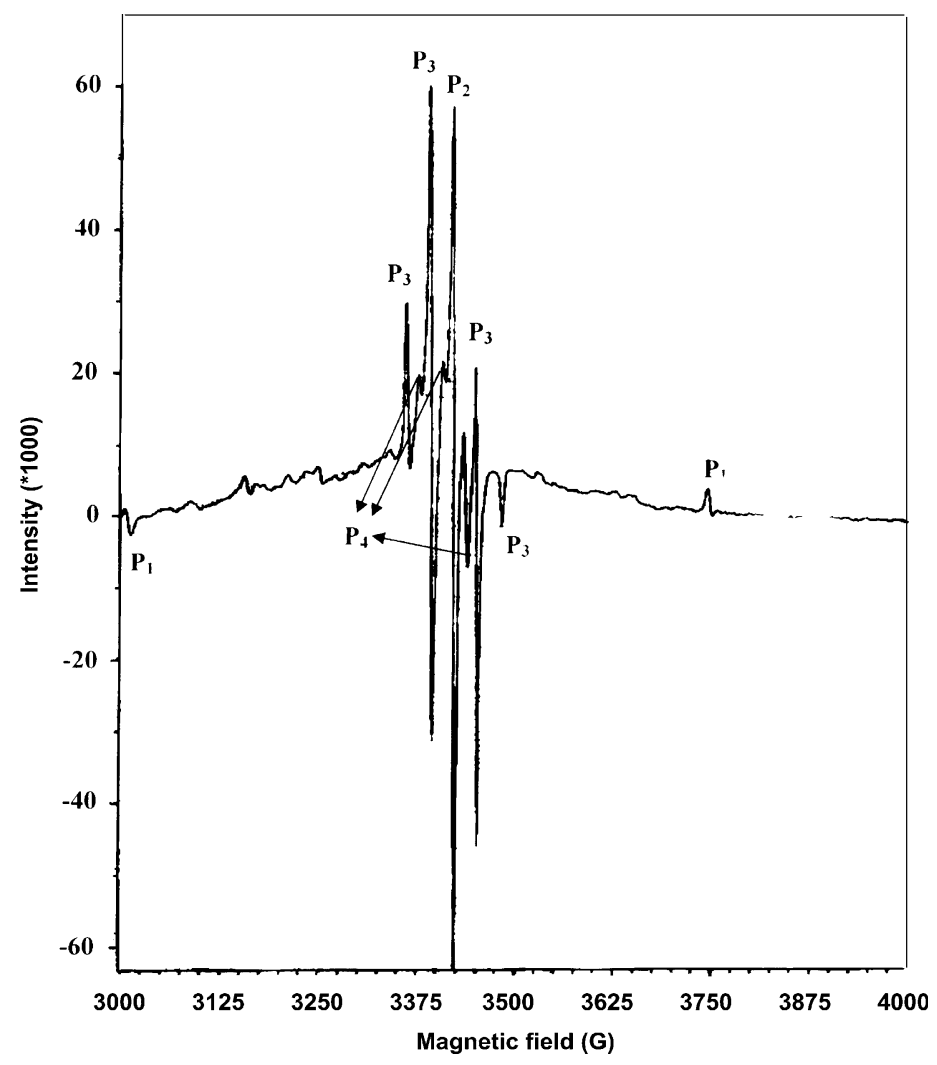

Fig. 4. EPR spectrum of gamma-ray irradiated-undoped $\mathrm{Sr}_{2} \mathrm{P}_{2} \mathrm{O}_{7}$ (dose $=4 \mathrm{kGy}$ ) at room temperature. Signals marked as $\mathrm{P}_{1}$ (doublet), $\mathrm{P}_{2}, \mathrm{P}_{3}$ (quartet) and $\mathrm{P}_{4}$ (triplet) are discussed in the text.

origin ( $\mathrm{P}_{3}$ center). Furthermore, the EPR spectrum of the $4 \mathrm{kGy}$ irradiated sample was recorded in second harmonic mode in order to resolve the triplet $\left(\mathrm{P}_{4}\right.$ center) overlapping with signal of $\mathrm{P}_{3}$ centers (Fig. 5). Signal of $\mathrm{P}_{4}$ center has $g=2.0052$ and $A=30 \mathrm{G}$. The temperature dependence of the EPR spectrum of the sample was carried out in the temperature range of 300-575 K. On heating above room temperature, the intensity of the composite signal decreases at $525 \mathrm{~K}$ (Fig. 6). However, on heating at $575 \mathrm{~K}$, this composite signal disappears. Interestingly, on cooling the sample to $77 \mathrm{~K}$, it did not appear again indicating that the center associated with this signal got destroyed.

Strontium pyrophosphate subjected to gamma-ray irradiation might yield different ${ }^{31} \mathrm{P}$ (natural abundance $=100 \%$ and nuclear spin, $I=1 / 2$ ) centered radicals, viz. $\mathrm{PO}^{2-}, \mathrm{P}_{2} \mathrm{O}_{7}{ }^{3-}, \mathrm{PO}_{2}{ }^{2-}, \mathrm{PO}_{3}{ }^{2-}$ and $\mathrm{PO}_{4}{ }^{2-}$ as reported in literature [14-16]. $\mathrm{P}_{1}$ center obtained in the present study is attributed to $\mathrm{PO}_{3}{ }^{2-}$ radical with its large hyperfine coupling coming from electron in the $3 \mathrm{~s}$ orbital. $\mathrm{P}_{3}$ center has smaller hyperfine splitting, but not as small as reported [14] for $\mathrm{PO}_{4}{ }^{2-}$ and $\mathrm{P}_{2} \mathrm{O}_{7}{ }^{3-}$ ions. However, it is close to the one reported for $\mathrm{PO}_{2}{ }^{2-}$ center in $\mathrm{KCl}$ [15]. Hence, the intense quartet signal is attributed to axially distorted $\mathrm{PO}_{2}{ }^{2-}$ centers and the close resemblance of its $g$ values $\left(g_{\perp}=2.0041\right.$ and $\left.g_{\|}=2.0042\right)$ suggests isotropic nature of the radical. The signal of $\mathrm{P}_{2}$ centers, with $g_{\perp}=2.0047$ and $g_{\|}=2.0030$, overlapping with low-field parallel component of $\mathrm{P}_{3}$ center is assigned to $\mathrm{O}_{2}{ }^{-}$radical ion on the basis of its $g$ values reported in apatites [16]. $\mathrm{P}_{4}$ center could not be identified. 


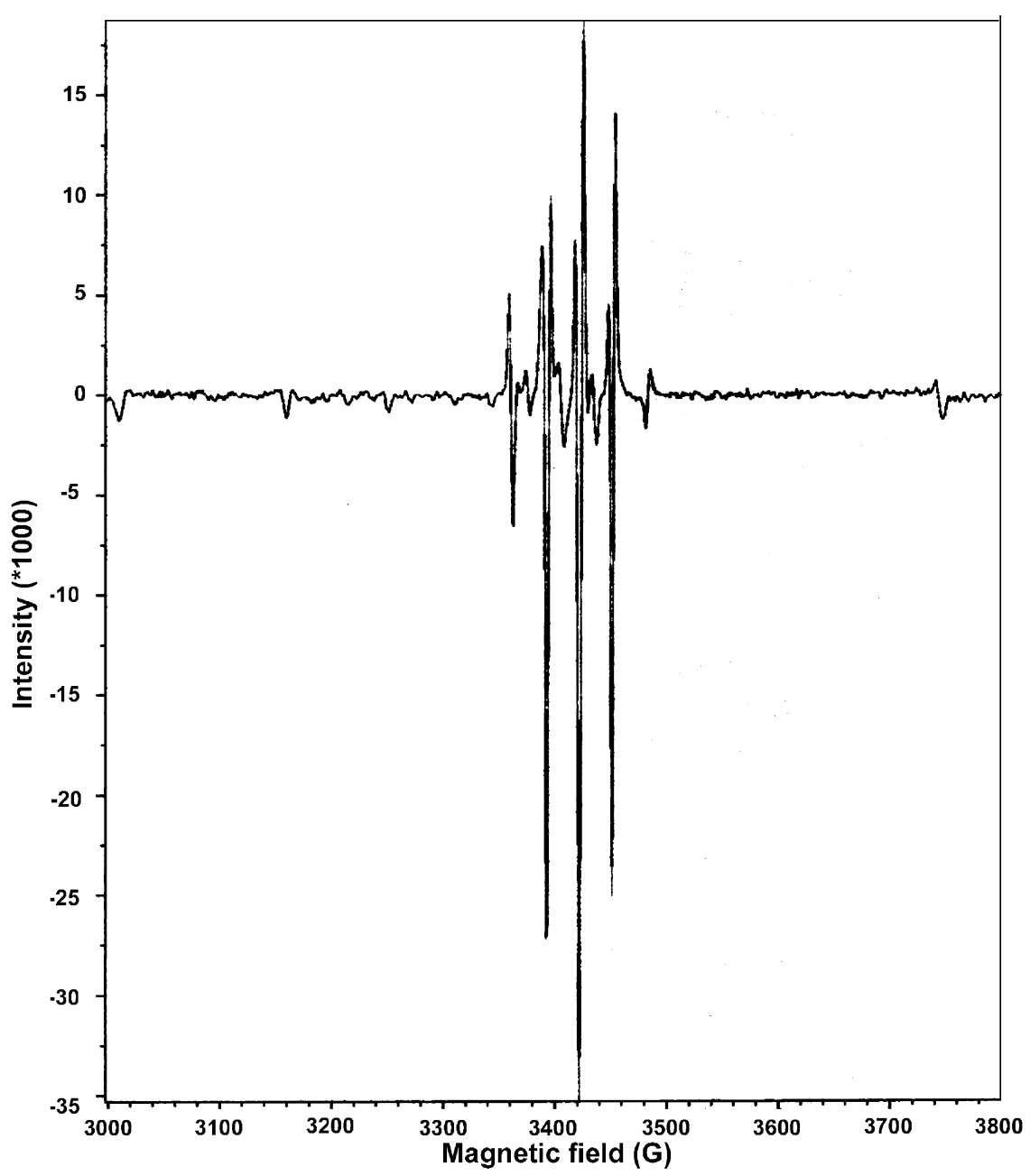

Fig. 5. Second harmonic EPR spectrum of gamma-ray irradiated $\mathrm{Sr}_{2} \mathrm{P}_{2} \mathrm{O}_{7}$ at room temperature.

EPR spectra of the unirradiated and gamma irradiated Eu-ion doped $\mathrm{Sr}_{2} \mathrm{P}_{2} \mathrm{O}_{7}$ sample were recorded at room temperature and $77 \mathrm{~K}$. The spectra of both unirradiated and irradiated samples showed signals in the 320-370 mT region. (Fig. 7). The signals consisted of two sets of sextet hyperfine lines with $A=92 \mathrm{G}$ (a) and $A=94 \mathrm{G}(\mathrm{b})$, respectively, and slightly different $g$ values $(g=2.0032$ and 2.0024). These lines are characteristic of $\mathrm{Mn}^{2+}$ ions as reported in the literature [17,18], indicating that $\mathrm{Mn}^{2+}$ has entered the lattice (at two different $\mathrm{Sr}^{2+}$ sites) as an impurity from the analytical grade reagents used for the preparation, namely strontium nitrate or diammonium hydrogen phosphate. Similarly, weak $\mathrm{Mn}^{2+}$ lines are observed in the undoped $\mathrm{Sr}_{2} \mathrm{P}_{2} \mathrm{O}_{7}$ samples.

The hyperfine lines from $\mathrm{Eu}^{2+}\left(\mathrm{Eu}^{151,153}\right)$ expected in the 340-360 $\mathrm{mT}$ (3.4-3.6 kG) region (with A $30 \mathrm{G}$ for $\mathrm{Eu}^{151}$ and $\sim 15 \mathrm{G}$ for $\mathrm{Eu}^{153}$ [19], respectively, and $g$ around 2.000) seem to be hidden under strong $\mathrm{Mn}^{2+}$ lines. The spectra also show signals from $\mathrm{PO}_{2}{ }^{2-}\left(\mathrm{P}_{3}\right)$ and $\mathrm{O}_{2}{ }^{-}\left(\mathrm{P}_{2}\right)$ radical ions around $g=$ 2.0042, similar to those observed in undoped irradiated $\mathrm{Sr}_{2} \mathrm{P}_{2} \mathrm{O}_{7}$. EPR spectra of gamma-ray irradiated 


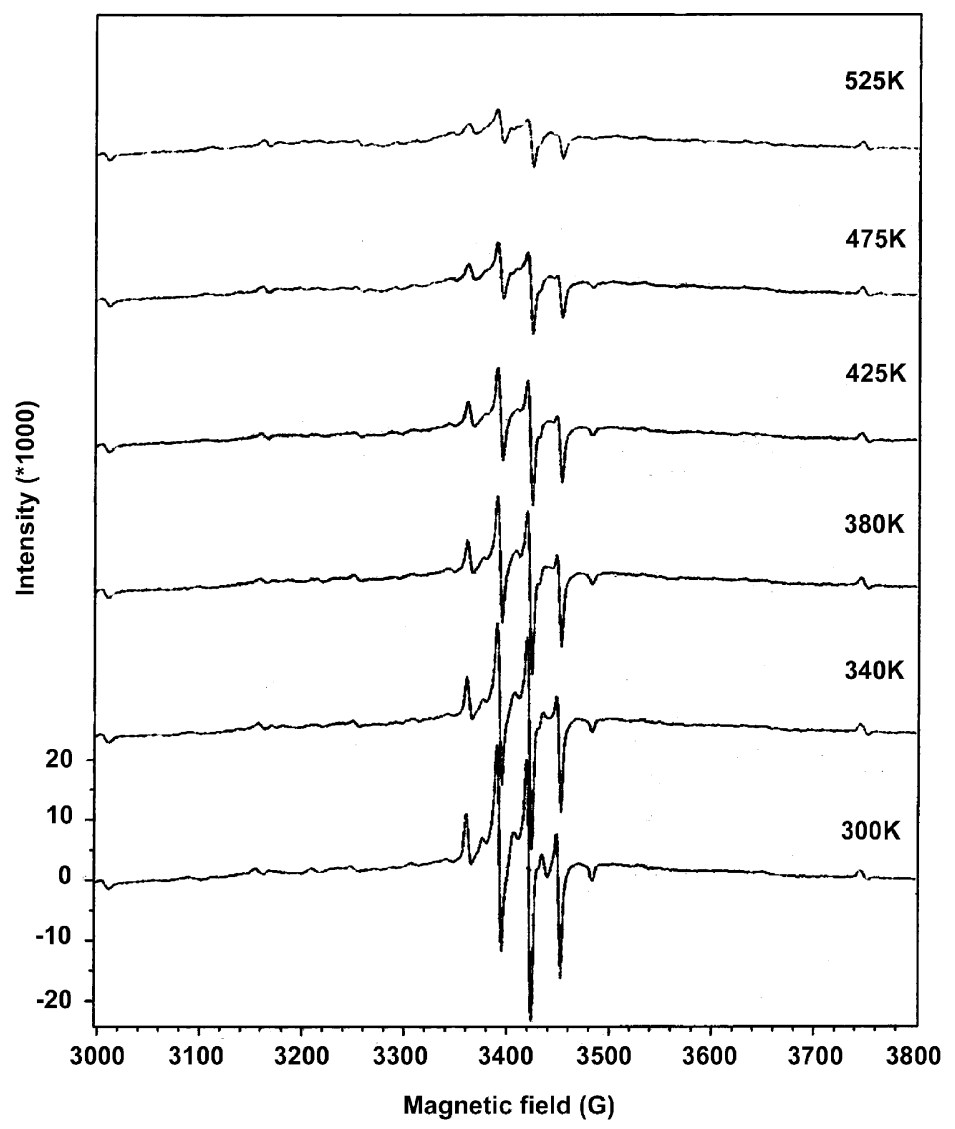

Fig. 6. EPR spectra of gamma-ray irradiated $\mathrm{Sr}_{2} \mathrm{P}_{2} \mathrm{O}_{7}$ recorded at various temperatures.

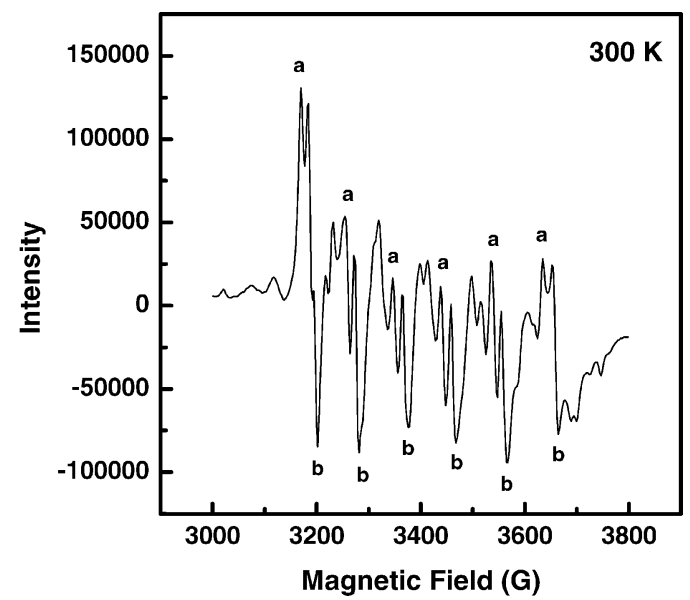

Fig. 7. EPR spectrum of unirradiated Eu-ion doped $\mathrm{Sr}_{2} \mathrm{P}_{2} \mathrm{O}_{7}$ at room temperature. The two sets of hyperfine lines from $\mathrm{Mn}^{2+}$ ion $\left(\mathrm{Mn}^{55}\right)$ at two different sites are marked ' $\mathrm{a}$ ' and ' $\mathrm{b}$ ' in the figure. 


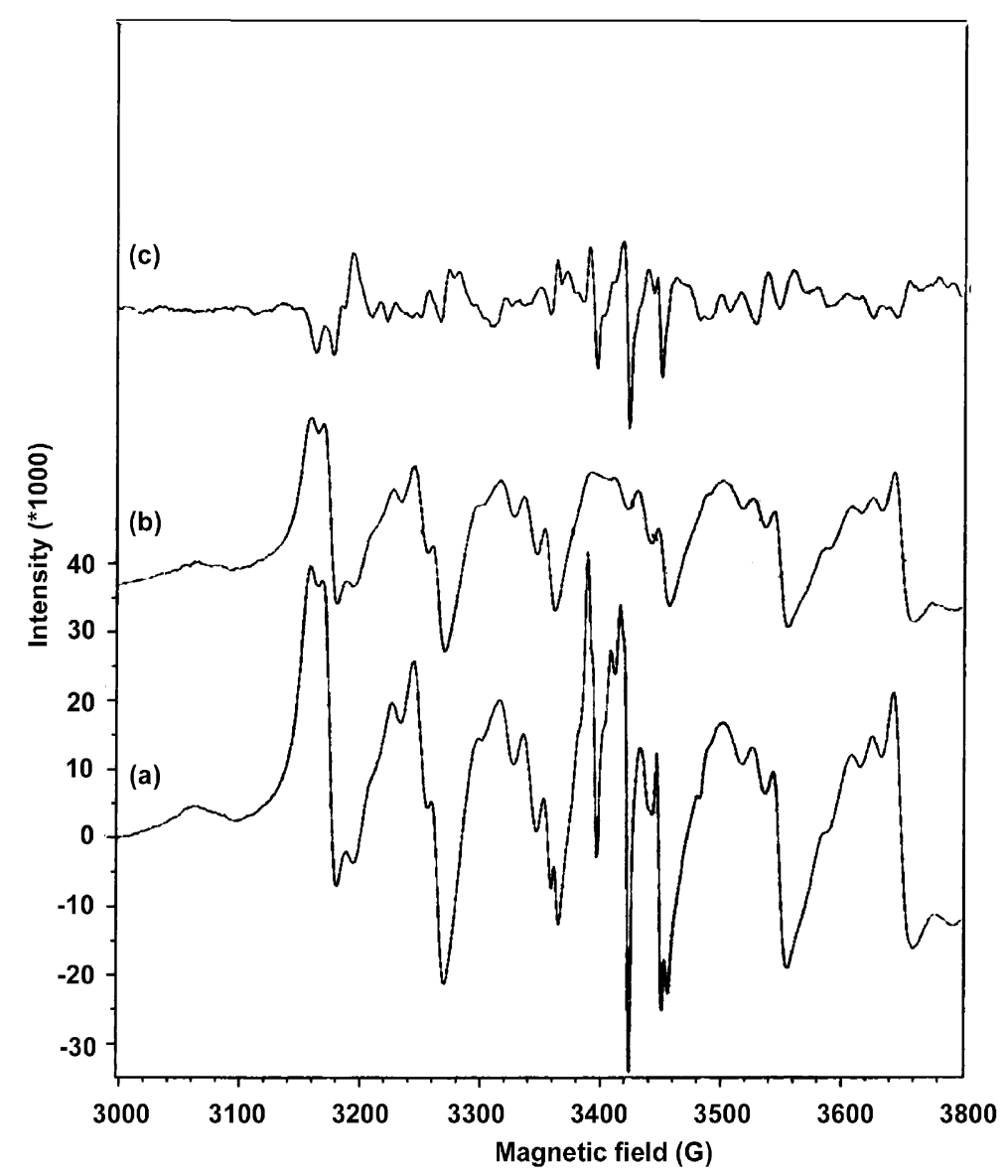

Fig. 8. EPR spectra recorded at $100 \mathrm{~K}$ : (a) gamma-ray irradiated sample; (b) gamma irradiation followed by annealing at $575 \mathrm{~K}$; and (c) difference between spectrum a and spectrum $b$.

Eu-ion doped $\mathrm{Sr}_{2} \mathrm{P}_{2} \mathrm{O}_{7}$ samples were recorded in the $100-500 \mathrm{~K}$ range. On heating above the room temperature, the intensity of the signals from $\mathrm{PO}_{2}{ }^{2-}$ and $\mathrm{O}_{2}{ }^{-}$radicals decreases, while further heating at $575 \mathrm{~K}$, signals of both the radicals disappear together (Fig. 8). This behavior of these two radical ions is similar to that observed in undoped samples. The destruction of these radical ions around $575 \mathrm{~K}$ strongly suggests their role in the TSL peak in Eu-ion doped $\mathrm{Sr}_{2} \mathrm{P}_{2} \mathrm{O}_{7}$ at this temperature. In view of these results, the mechanism for the $565 \mathrm{~K}$ glow peak is confirmed to be due to the recombination of $\mathrm{PO}_{2}{ }^{-}$and $\mathrm{O}_{2}{ }^{-}$ ions and the associated energy transfer to nearby $\mathrm{Eu}^{3+}$ ions.

The spectra of gamma irradiated europium-ion doped $\mathrm{Sr}_{2} \mathrm{P}_{2} \mathrm{O}_{7}$ recorded at $175 \mathrm{~K}$ consist of several broad signals over a wide range of magnetic-field $(0-200 \mathrm{mT})$; but these signals are quite weak as compared to those observed around $340 \mathrm{mT}$ (Fig. 9). It is noted that these features are absent in the unirradiated samples. Such a spectrum is reported to be typical of $\mathrm{Eu}^{2+}$ ion with large zero-field splitting and might be a pointer to the presence of $\mathrm{Eu}^{2+}$ at a low symmetry site as in the case of $\mathrm{SrBPO}_{5}: \mathrm{Eu}^{2+}[20]$. This signal is probably associated with $\mathrm{Eu}^{2+}$ ions formed on gamma-ray irradiation due to electrons captured by $\mathrm{Eu}^{3+}$ ions. 


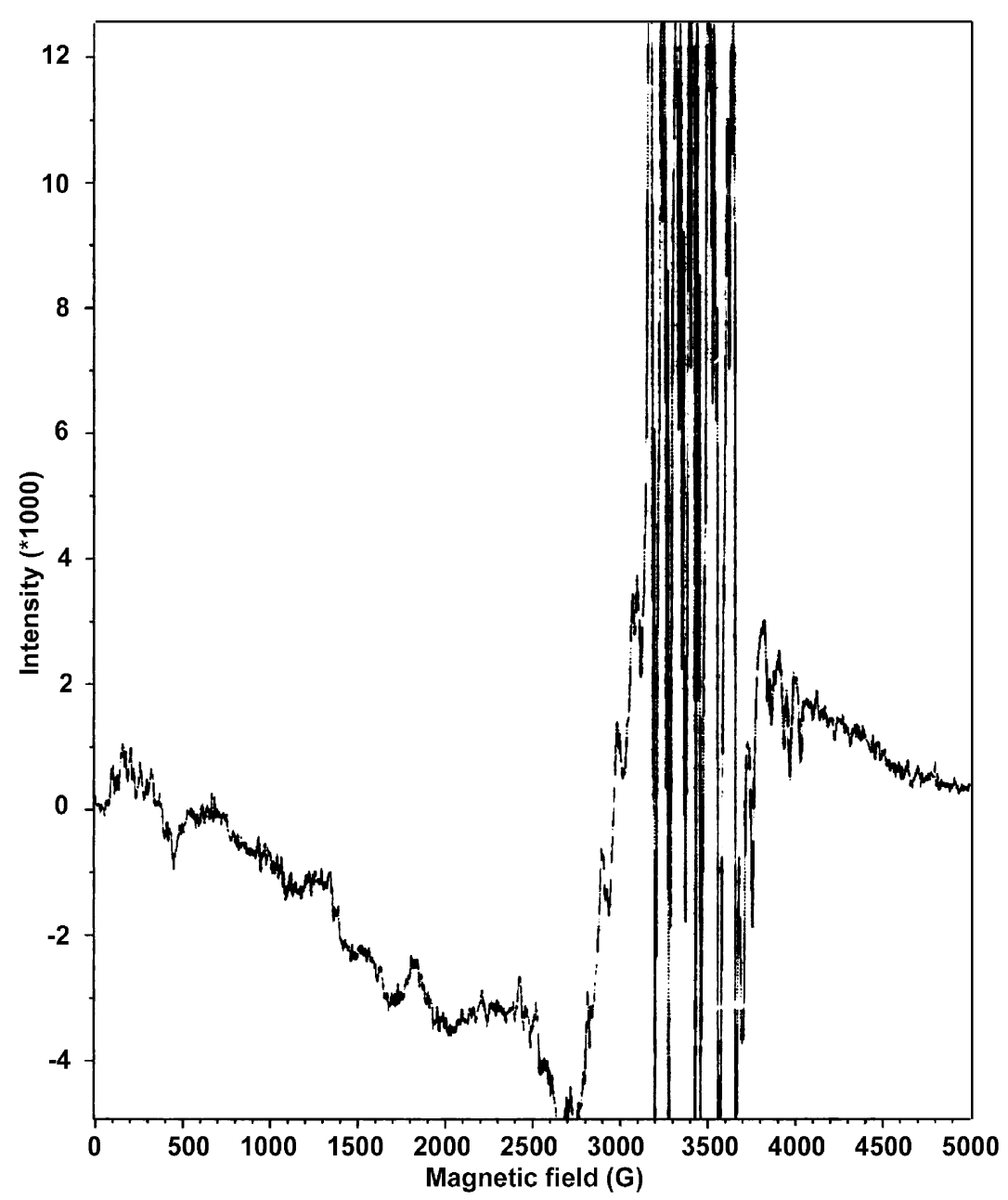

Fig. 9. EPR spectrum of gamma-ray irradiated Eu-ion doped $\mathrm{Sr}_{2} \mathrm{P}_{2} \mathrm{O}_{7}$ recorded at $175 \mathrm{~K}$ in the $0-4500 \mathrm{mT}$ range.

\section{Conclusion}

The present investigation on Eu-ion doped strontium pyrophosphate sample prepared via a chemical precipitation method followed by heating in nitrogen indicates that europium ions were present both in divalent as well as trivalent oxidation states in the sample. Fluorescence life time measurements revealed that $\mathrm{Eu}^{3+}$ ion existed at two different environments in the lattice. Two glow peaks were observed in gamma irradiated europium ion doped samples at 465 and $565 \mathrm{~K}$. $\mathrm{Eu}^{3+}$ ion was identified as the luminescent center for the glow peaks. In gamma irradiated samples, $\mathrm{PO}_{2}{ }^{2-}, \mathrm{PO}_{3}{ }^{2-}$ and $\mathrm{O}_{2}{ }^{-}$radical ions were observed. By correlating the TSL and EPR results on europium-ion doped $\operatorname{Sr}_{2} \mathrm{P}_{2} \mathrm{O}_{7}$, the mechanism for the glow peak at $565 \mathrm{~K}$ was identified. 


\section{References}

[1] S. Shionoya, W.M. Yen, Phosphor Hand Book, CRC Press, Washington DC, 1999, pp. 391-432.

[2] S.H.M. Poort, W.P. Blokpoel, G. Blasse, Chem. Mater. 7 (1997) 1547-1551.

[3] S.H.M. Poort, W. Janssen, G. Blasse, J. Alloys Compd. 260 (1997) 93-97.

[4] J.K. Park, M.A. Lim, C.H. Kim, H.D. Park, Appl. Phys. Lett. 82 (2003) 683-685.

[5] Y. Murayama, N. Takeuchi, Y. Aaoki, T. Matsuzawa, US patent 5424006 (1995).

[6] S.J. Dhoble, S.V. Moharil, J. Phys. D. Appl. Phys. 33 (2000) 158-161.

[7] G. Blasse, B.C. Grabmaier, Luminescent Materials, Springer Verlag, Berlin Heidelberg, 1994, p. 127.

[8] A.M. Srivastava, US patent Application 0030067008 (2003).

[9] G. Blasse, W.L. Wanmaker, J.W. Ter Vrught, J. Electrochem. Soc. 115 (1968) 673.

[10] H. Miyoshi, T. Yoshino, Radiat. Phys. Chem. 48 (1996) 315-318.

[11] Powder Diffraction File, Card no. 24-1011, Joint Committee on Powder Diffraction Standards, Swathmore, PA.

[12] G. Blasse, B.C. Grabmaier, Luminescent Materials, Springer Verlag, Berlin Heidelberg, 1994, pp. 41-43.

[13] J.C. Grenier, R. Masse, Bulletin de la Societe Francaise de Minerologie et de Cristallographie 90 (1967) $285-292$.

[14] S. Subramanian, M.C.R. Symons, H.W. Wardale, J. Chem. Soc. A (1970) 1239-1241.

[15] F. Callens, F. Maes, P. Moens, P. Matthys, E. Boesman, J. Phys. Condens. Matter 4 (1992) 6593-6602.

[16] A.S. Marfunin, Spectroscopy Luminescence and Radiation Centers in Minerals, Springer, New York, 1979, pp. $258-261$.

[17] R.S. de Biasi, M.L.J. Grillo, J. Phys. Chem. Solids 64 (2003) 1365-1369.

[18] R.S. de Biasi, J. Am. Ceram. Soc. 86 (2003) 195-196.

[19] N. Yamashita, J. Lumin. 59 (1994) 195-199.

[20] T. Nakamura, T. Takeyama, N. Takahashi, R. Jagannathan, A. Kartikeyani, G.M. Smith, P.C. Reidi, J. Lumin. 102-103 (2003) 369-372. 